\title{
Desigualdad: ¿Que Podemos hacer? De Antony Atkinson.
}

La desigualdad es un tema recurrente en los análisis políticos y académicos. Barack Obama, premio Nobel de Paz del 2009, mencionó en su discurso para el Center for American Progress (Centro para el progreso americano) en diciembre 4 de 2013 que "la desigualdad está definiendo nuestro tiempo" (Newell, 2013), de esta manera puso de manifiesto la importancia que tiene dicho problema y qué tantot requiere un cambio de enfoque frente a lo que se venía trabajando'. Sin duda alguna, el trabajo de Piketty (2015) y su libro El capital del siglo XX/ reforzó la idea de que la desigualdad requiere una aproximación que vaya más allá de los recursos directamente disponibles, una disposición política más abierta a soluciones que se salgan un poco de los canales de la ortodoxia, ya que las predicciones del "modelo copa" o "desbordamiento" llegan a muy pocas personas.

La obra de Atkinson Desigualdad. ¿Qué podemos hacer?, trata justamente de visualizar perspectivas diferentes de soluciones ante el problema de la desigualdad, demarca una inusitada importancia sobre la toma de consciencia acerca de este fenómeno. Utiliza alguna forma de la duda metódica sobre aspectos como significado, dimensión y experiencia para presentar un conjunto de datos, hechos, definiciones y propuestas que dan herramientas a los hacedores de políticas (policy-makers) para afrontar el problema actual, y brinda herramientas para el tratamiento futuro de la cuestión.

La primera parte de la obra está compuesta por tres capítulos que presentan un diagnóstico del estado actual de la desigualdad en el mundo. Muestra los diferentes conceptos y matiza la diferencia entre la desigualdad de oportunidades -asociada a las circunstancias del individuo como determinante- $y$ las desigualdades de resultados, asociadas a los "premios" presentes y la manera en que los individuos los trasladan a futuro (herencias). También realiza una exposición de los tipos de ingresos y refiere cuáles trabajar según las necesidades de estudios sobre desigualdad del ingreso (salario), la renta, la riqueza, el consumo, entre otros. De esta manera, deja implícitos los asuntos de la redistribución, la cual se da posterior a una política de rentas enfocada en mejorar la distribución, un antes y después.

La segunda parte (capítulos 4 a 8) ilustra fundamentalmente, el hecho de que la desigualdad se encuentra en diferentes niveles,

* Estudiante de Doctorado en Economía Aplicada, Universidad Autónoma de Barcelona. Orcid: https://orcid.org/0000-0002-4625-4722

1 En principio se consideraba que la desigualdad era un aspecto residual del proceso económico. 
tanto en lo económico como en lo social. En relación con el primero dilucida aspectos como el cambio tecnológico y su influencia en la distribución de salarios, el poder compensatorio de los servicios sociales, el mercado de capitales y los impuestos progresivos. En lo social hace alusión al mercado laboral, la participación de la riqueza de los deciles superiores en el PIB, el poder de mercado (monopolios o monopsonios en su forma más primitiva o versiones intermedias de ellos) $y$ estado del bienestar (sistema de pensiones o subsidios educativos) como complementos a un ingreso participativo, por ejemplo los programas de transferencias condicionadas. Al final del capítulo 8 presenta 15 propuestas para reducir la desigualdad, a saber:

Propuesta 1. La dirección del cambio tecnológico debe ser una preocupación explícita de los hacedores de política, alentando la innovación en una forma que incremente las cualidades laborales de los trabajadores y acentúe la dimensión humana de la disposición de servicio.

Propuesta 2. La política pública debe proponerse un equilibrio de poder adecuado entre las partes interesadas, y para este propósito debe a) introducir explícitamente una dimensión distributiva en la política de competencia; b) asegurar un marco legal que permita a los sindicatos representar a los trabajadores en términos equitativos, y c) establecer, donde no exista, un Consejo Social y Económico que involucre a los actores sociales y otros organismos no gubernamentales.

Propuesta 3. El gobierno debe adoptar un objetivo explícito de impedir y reducir el desempleo y reforzar esta ambición ofreciendo empleo público garantizado al salario mínimo a quienes lo buscan.
Propuesta 4. Debe haber una política nacional de remuneraciones, consistente en dos elementos: un salario mínimo estatutario fijado al nivel de un salario digno y un código de práctica para remuneraciones por encima del mínimo, acordado como parte de "un diálogo nacional" que involucre al Consejo Social y Económico.

Propuesta 5. El gobierno debe ofrecer, mediante bonos de ahorro nacional, una tasa de interés real positiva garantizada de los ahorros, con una inversión máxima por persona.

Propuesta 6. Debe haber una dotación de capital (herencia mínima) que se pague a todos en la edad adulta.

Propuesta 7. Debe crearse una Autoridad de Inversión pública que opere un fondo de riqueza soberana con el propósito de acrecentar el valor neto del Estado manteniendo inversiones en compañías y en propiedades.

Propuesta 8. Debemos volver a una estructura más progresiva para el impuesto al ingreso personal, con tasas marginales de impuestos que aumenten en rangos de ingreso gravable hasta una tasa tope de $65 \%$, acompañada por un ensanchamiento de la base gravable.

Propuesta 9. El gobierno debe incorporar al impuesto al ingreso personal un Descuento del Ingreso Ganado, limitado a la primera banda de ingresos.

Propuesta 10. Los ingresos de herencia y regalos inter vivos deben gravarse bajo un impuesto de ingresos de capital vitalicio progresivo.

Propuesta 11. Debe haber un impuesto a la propiedad proporcional, o progresivo, basado en evaluaciones actualizadas de la propiedad. 
Propuesta 12. El Subsidio Infantil debe pagarse a todos los niños a una tasa sustancial y debe gravarse como ingreso.

Propuesta 13. Debe introducirse un ingreso de participacióna nivel nacional, complementando de esta manera la protección social existente, con la perspectiva de una renta básica infantil de toda la Unión Europea.

Propuesta 14. Debe haber una renovación de la seguridad social que eleve el nivel de subsidios y extienda su cobertura.

Propuesta 15. Los países ricos deben elevar su objetivo de la Asistencia del Desarrollo Oficial a $1 \%$ del ingreso nacional bruto.

Por otra parte, el autor plantea unas ideas que se pueden explorar como nuevos elementos para direccionar las investigaciones a futuro:

Una revisión completa del acceso de los hogares al mercado de crédito de modo que la vivienda no funja como la garantía que asegura el préstamo; [e]xamen del caso para un tratamiento del "impuesto basado en el ingreso" de las aportaciones a las pensiones privadas, consistente con los planes de ahorro "privilegiados" actuales, lo cual traería consigo el pago de impuestos; [u]na reexaminación del caso de un impuesto a la riqueza anual y los prerrequisitos para su introducción exitosa; [i] dea para explorar: [u]n régimen de impuesto global para contribuyentes personales, basado en la riqueza total; [u]n impuesto mínimo para corporaciones.

Finalmente, los detalles de las críticas a las propuestas se muestran del capítulo noveno "¿Reducción del pastel?" al onceavo, con la forma de abordarlos. En resumen, es una obra que aborda con profundidad la desigualdad y sus posibles soluciones que, si bien no se configuran como recetas estilo step by step (paso a paso), se pueden considerar un punto de partida para los hacedores de política (policy makers). En esta obra, Atkinson logra con rigor analítico despertar el interés necesario para comprender las vicisitudes que representa la desigualdad, sus críticas, sus posibles soluciones y un recetario de propuestas de investigaciones a futuro. Es una publicación que no deja indiferente al lector formado en economía y en otras profesiones. Por último, cabe agregar que el trabajo de Anthony B. Atkinson sobre desigualdad es equivalente al trabajo de Rudiger Dornbusch en Macroeconomía Internacional, un nobel "póstumo" pendiente. Con deseo, espero la presente reseña sea el abrebocas para realizar la lectura del libro.

\section{Referencias}

Atkinson, A. B. (2015). Desigualdad ¿Qué podemos hacer? Fondo de Cultura Económica.

Newell, J. (2013, diciembre 4). Obama: income inequality is 'defining challenge of our time' live. The Guardian. https://www.theguardian. com/world/2013/dec/04/obama-incomeinequality-minimum-wage-live

Piketty, T. (2015). El capital en el siglo XXI. Fondo de Cultura Económica. 